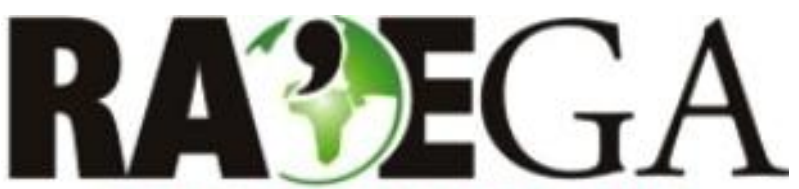

O ESPAÇO GEOGRÁFICO EM ANÁLISE

\title{
ARQUEOLOGIA DA PAISAGEM APLICADA AO ESTUDO DE SÍTIOS ARQUEOLÓGICOS JÊ MERIDIONAIS NAS BACIAS HIDROGRÁFICAS DOS RIOS FORQUETA E GUAPORÉ/RIO GRANDE DO SUL
}

\section{LANDSCAPE ARCHAEOLOGY APPLIED TO STUDY ARCHAEOLOGICAL SITES FROM SOUTHERN JE GROUPS AT BASINS OF THE FORQUETA AND GUAPORÉ RIVERS/STATE OF RIO GRANDE DO SUL}

\author{
Sidnei Wolf ${ }^{1}$, Neli Galarce Machado ${ }^{2}$
}

\begin{abstract}
RESUMO
A arqueologia tem demonstrado como as populações do passado gerenciavam seu espaço e território ao longo do tempo, e de que maneira essa distribuição se refletiu nas relações sociais entre os indivíduos. A Arqueologia da Paisagem se apresenta como uma excelente perspectiva de entendimento nesse sentido, englobando diferentes concepções dentro do mesmo conceito: ambientais, sociais e simbólicas. Para o caso dos sítios arqueológicos de populações Jê Meridionais se observa uma relação de complementação entre os sítios de estruturas subterrâneas e superficiais, associados a diferentes atividades. O objetivo deste artigo é entender a distribuição destas duas categorias de sítios pelas bacias hidrográficas dos rios Forqueta e Guaporé, Rio Grande do Sul. A metodologia esteve baseada na localização dos assentamentos em uma área piloto de $440 \mathrm{~km}^{2}$, na escavação de 03 sítios arqueológicos e realização de datações radiocarbônicas. Os resultados demonstraram uma preferência dos sítios de estruturas subterrâneas, relacionadas ao maior convívio social, às áreas de maior altitude, à Floresta Ombrófila Mista e à vegetação campestre; já os sítios superficiais, vinculados às atividades específicas, como o manejo agroflorestal, estão coadunados, predominantemente, à transição entre a Floresta Ombrófila Mista e a Floresta Estacional Decidual. Interpretam-se os resultados como reflexo da existência de dois espaço distintos na região: um dominado por estruturas subterrâneas, localizadas dentro de um raio de $2,2 \mathrm{~km}$ entre si, e outra área relacionada aos sítios superficiais, longe destes centros.
\end{abstract}

Palavras chave: Rio Forqueta; Rio Guaporé; Estruturas Subterrâneas; Paisagem; Arqueologia Jê.

\section{ABSTRACT}

Archeology has demonstrated how the populations of the past have managed their space over time, and how this distribution reflected in the social relations between individuals. Landscape Archeology presents itself an excellent perspective of understanding this sense, encompassing different conceptions within the same concept: environmental, social and symbolic. For the case of the archaeological sites of Southern Je people, a complementary relationship between pit houses and surface sites associated to different activities is observed. The objective of this article is to understand the distribution of these two categories of sites basins Forqueta and Guaporé river, State of Rio Grande do Sul, Brazil. The methodology was based on the location of the settlements in a pilot area of $440 \mathrm{~km}^{2}$, in the excavation of 03 archaeological sites and realization radiocarbon dating. The results demonstrated a preference of the underground structures site for pit house sites, linked to greater social interaction, to the higher altitude areas, to the Mixed Ombrophylous Forest and the rural vegetation; the surface sites linked to specific activities, such as agroforestry management, are predominantly linked to the transition between the Mixed Ombrophylous Forest and the Decidual Seasonal Forest. The results are interpreted as reflecting the existence of two distinct spaces in the region: one dominated by subterranean structures, located within a radius of $2.2 \mathrm{~km}$ between them, and another area related to superficial sites, far from these centers.

Keywords: Forqueta river; Guaporé river; Pit Houses; Landscape; Je Archaeology.

Recebido em: 18/09/2017

Aceito em: 02/18/2018

\footnotetext{
${ }^{1}$ Universidade do Vale do Taquari, Lajeado/RS, email: sidneiwolf@universo.univates.br

${ }^{2}$ Universidade do Vale do Taquari, Lajeado/RS, email: ngalarce@univates.br
} 


\section{ARQUEOLOGIA DA PAISAGEM APLICADA AO ESTUDO DE SÍTIOS ARQUEOLÓGICOS JÊ MERIDIONAIS NAS BACIAS HIDROGRÁFICAS DOS RIOS FORQUETA E GUAPORÉ/RIO GRANDE DO SUL}

\section{INTRODUÇÃO}

As relações dos seres humanos com o ambiente e o espaço são os pontos chave desta pesquisa. Ao se trabalhar com populações précoloniais essa tarefa torna-se ainda mais necessária ao identificar as influências dos grupos nos sistemas ecológicos, sociais e no gerenciamento de estratégias de assentamento e permanência no tempo e no espaço.

As populações Jê Meridionais que habitaram o Sul do Brasil, além dos estados de São Paulo e Mato Grosso do Sul, e da província de Misiones na Argentina (NOELLI, 2004) durante os últimos 2000 anos, estiveram associadas a um sistema baseada numa intensa mobilidade pelo território, abrangendo o litoral, as encostas e o Planalto, onde predominam sítios de estruturas subterrâneas (SCHMITZ et al., 1988; BEBER, 2004, NOELLI, 2004).

Associadas a unidades habitacionais (SCHMITZ et al., 2002, BEBER, 2004; COPÉ, 2006), apresentam diversos tamanhos e profundidades. Normalmente se encontram isoladas, ou em conjuntos de até 3 estruturas, ocorrendo também assentamentos com altas densidades, chegando a 107 (BEBER, 2004; SCHMITZ e ROGGE, 2011). No entorno próximo dos sítios são encontrados outros assentamentos de diferentes funcionalidades, como cerimoniais e funerários (SALDANHA, 2005; DE SOUZA, 2012; IRIARTE et al., 2013), e áreas de atividades específicas relacionadas ao manejo agroflorestal (DIAS, 2003; SALDANHA, 2005).

O objetivo deste trabalho é analisar a distribuição dos sítios de estruturas subterrâneas e superficiais associados às populações Jê Meridionais nas bacias hidrográficas dos rios Forqueta e Guaporé, Rio Grande do Sul, tomando como referência a paisagem enquanto espaço social em que se desenvolvem as relações entre os grupos humanos ao longo do tempo (CRIADO BOADO, 1999).

\section{PAISAGEM E ARQUEOLOGIA}

A arqueologia possui como um dos objetivos principais o entendimento da relação entre humanos e seu ambiente, a partir de suas inter-relações com a natureza. Ao longo do tempo a compreensão destes fenômenos contemplou diferentes visões, ora mais ambientais, ora culturais. As interpretações foram moldadas por perspectivas teóricas que variaram de acordo com as tradições e mudanças dos meios sociais e políticos. Todas, no entanto, compartilham a preocupação central de como os seres humanos interagem com o mundo ao seu redor (ASHMORE e BLACKMORE, 2008).

Entende-se a paisagem como uma entidade que ultrapassa as características físicas de um espaço, ligada a uma apropriação e remodelação, com vias a formulação de um território, imbricado de uma significação econômica e simbólica, resultado de uma ação humana que mudou a realidade natural e criou espaços humanos e humanizados.

A análise de paisagem na Arqueologia é recente, iniciada a partir da década de 1970. A Arqueologia da Paisagem, como proposta, remonta sua origem a uma perspectiva geográfica da Ecologia da Paisagem, desenvolvida na Europa. Nesta visão, a paisagem é concebida como uma entidade visual e espacial conectada à vivência humana (METZGER, 2001).

O conceito de paisagem na Arqueologia pré-colonial está amarrado intimamente à paisagem cultural, que incide na relação dos povos do passado com o ambiente. Essas relações podem consistir em influências naturais/ambientais, sociais, culturais ou espirituais/simbólicas, sendo a Arqueologia da Paisagem uma ferramenta para interpretação de cada um destes tipos de relacionamentos (FÖRSTER et al., 2013). Os sistemas econômicos, sociais e políticos se tornam resultados de estratégias de gerenciamento da paisagem, onde o ambiente é unicamente tido como resultado de uma construção humana, sendo a paisagem antropogenizada.

Nesse sentido, Bender (1993, p.1) argumenta que as paisagens são criadas por pessoas - através de sua experiência e envolvimento com o mundo em torno delas -, sendo parte presente da vida humana, "a paisagem nunca é inerte, envolvendo pessoas 


\section{ARQUEOLOGIA DA PAISAGEM APLICADA AO ESTUDO DE SÍTIOS ARQUEOLÓGICOS JÊ MERIDIONAIS NAS BACIAS HIDROGRÁFICAS DOS RIOS FORQUETA E GUAPORÉ/RIO GRANDE DO SUL}

que as apropriam e contestam. Faz parte de como as identidades são criadas e disputadas ${ }^{3 \prime}$.

Cosgrove (1984) concebe a paisagem como uma imagem, significada por uma forma de representar, estruturar e simbolizar o espaço físico do entorno. Como produto social e cultural, refere-se para um modo de ver projetada sobre a terra as formas de sua composição, numa visão alternativa e restritiva de experimentar as relações com a natureza.

A Arqueologia da Paisagem, como ferramenta para a interpretação da paisagem arqueológica, é antes de tudo uma arqueologia das pessoas e não do ambiente (DAVID; THOMAS, 2010, p.38).

Este, então, é o ponto crucial da Arqueologia da Paisagem: diz respeito não somente ao ambiente físico no qual os seres humanos vivem, mas também a locais significativos em que as vidas são vividas. Isso inclui árvores, rochas e estrelas, não como objetos abstratos, mas como elementos importantes localizados ontologicamente e experimentalmente nas vidas e práticas sociais. As pessoas estão no centro da Arqueologia da Paisagem e, condizente com o propósito geral de todas as arqueologias (em contraste com outras disciplinas), são as dimensões humanas do passado que uma Arqueologia da Paisagem objetiva ${ }^{4}$.

\footnotetext{
3 "the landscape is never inert, people engage with it, appropriate and contest it. It is part of the way in which identities are created and disputed" [original].

4 "This, then, is the crux of landscape archaeology: it concerns not only the physical environment onto which people live out their lives but also the meaningful location in which lives are lived. This includes the trees and the rocks and the stars, not as abstract objects but as meaningful things that are located ontologically and experientially in people's lives and social practices. People lie at the core of a landscape archaeology and,
}

Ingold (1993) sugere uma Arqueologia da Paisagem a partir do entendimento de como as pessoas visualizam o mundo e como elas se relacionaram com outras através do espaço, da escolha de locais a manipular seus arredores, ou como elas foram afetadas de forma subliminar a fazer as coisas por meio de características locais. Ou seja, engloba o intencional e o não intencional, o físico e o espiritual.

Para Ashmore e Blackmore (2008, p.1569) a Arqueologia da Paisagem engloba diferentes perspectivas, de acordo com características teóricas dos pesquisadores. Porém, ressaltam a necessidade de relacionamento com estratégias de poder.

Os estudos ecológicos examinam os efeitos das forças naturais, como o clima e a mudanças geomorfológicas, juntamente com as histórias políticas e econômicas do manejo da terra. Ao mesmo tempo, as paisagens podem ser entendidas como materializadoras da visão de mundo, produzindo espaços de memória social, identidade e história. As maneiras pelas quais as pessoas se envolvem com as paisagens culturais, moldam e refletem papéis e identidades sociais, incluindo gênero.(...). Em todas as multiplicidades, as paisagens são arenas para afirmar e resistir à autoridade ${ }^{5}$.

befitting the general purpose of all archaeologies (in contrast with others disciplines), it is those past human dimensions that a landscape archaeology targets" [original].

5 "Ecological studies examine effects of natural forces such as climate and geomorphic change, together with political and economic histories of land management. At the same time, landscapes can be understood as materializing worldview, yielding spaces of social memory, identity, and history. The ways people engage cultural landscapes shape and mirror social roles and identities, including gender. (...). In all varieties, 


\section{ARQUEOLOGIA DA PAISAGEM APLICADA AO ESTUDO DE SÍTIOS ARQUEOLÓGICOS JÊ MERIDIONAIS NAS BACIAS HIDROGRÁFICAS DOS RIOS FORQUETA E GUAPORÉ/RIO GRANDE DO SUL}

Entende-se a importância da paisagem, em suas diferentes escalas e níveis para uma compreensão da ocupação pretérita das bacias hidrográficas dos rios Forqueta e Guaporé. Nesse sentido, parte-se dos pressupostos de que o ambiente é dinâmico, construído e mantido pelos homens; de uma concepção de paisagem com ligações históricas; e a ideia de recorrência da amarração entre os humanos e suas paisagens (FISHER e THURSTON, 1999).

Com vistas à perspectiva de relação entre fatores ambientais, sociais, políticos, econômicos e simbólicos, num mesmo conceito de paisagem, alinha-se ao proposto por Criado Boado (1999, p.11), onde concebe a paisagem como um produto sociocultural criado “objetivação, sobre o meio e o espaço, da ação social de caráter material e imaginária. Esta ação social está constituída por práticas sociais (a ação social de caráter intencional: processos de trabalho, uso de técnicas, ritos, enunciação de discursos) como uma vida social ${ }^{6 \prime \prime}$.

O conceito de paisagem utilizado neste artigo reforça o entendimento como entorno social, partindo da compreensão de aspectos econômicos e políticos e da forma de organização do espaço pretérito Jê nas bacias hidrográficas dos rios Forqueta e Guaporé. Embora focado nesta perspectiva, se salientam as relações e inter-relações existentes entre as esferas sociais, ambientais e simbólicas, que compreendem diferentes percepções de um mesmo espaço.

\section{ARQUEOLOGIA JÊ}

A arqueologia de populações Jê Meridionais se apresenta como fonte de pesquisa desde a década de 1950. O sistema de assentamento abarcaria quatro categorias de

landscapes are arenas for asserting and resisting authority" [original].

6 "por la objetivación, sobre el medio y en términos espaciales, de la acción social tanto de carácter material como imaginario. Esta acción social está constituida tanto por las prácticas sociales (la acción social de carácter intencional: procesos de trabajo, utilización de técnicas, ritos, enunciación de discursos) como a vida social" [original]. sítios principais: estruturas subterrâneas (FIGURA 01), sítios líticos e líticos-cerâmicos na superfície, sepultamentos em abrigos, aterros anelares e montículos de terra funerários, e as estruturas subterrâneas (BEBER, 2004). Os abrigos com sepultamentos estão associados a funções funerárias, onde são depositados ou enterrados corpos sem cremação, podendo estar acompanhados a contas ou artefatos líticos (BEBER, 2004). Os aterros anelares e montículos estão adstritos às funções funerárias ou cerimoniais, destinados ao sepultamento de pessoas de alto status social dentro do grupo, ou para celebrações, como a perfuração dos lábios dos meninos (DEMASI, 2009; DE SOUZA, 2012; IRIARTE et al., 2013).

As estruturas subterrâneas se configuram como uma das principais características arqueológicas associadas às populações pré-coloniais Jê no Sul do Brasil. Sua presença é constatada a partir do século $\mathrm{V}$ da Era Cristã, estendendo-se até períodos posteriores a conquista europeia (SCHMITZ et al., 1988; BEBER, 2004), apesar de não existirem relatos dos conquistadores acerca deste tipo de estrutura. Costumam ocorrer isoladamente, aglomeradas em pequenos grupos, ou em grandes concentrações que podem chegar a 107 estruturas (SCHMITZ et. al, 2013). Normalmente possuem uma forma circular ou elíptica, com diâmetros inferiores a $5 \mathrm{~m}$, com ocorrências de estruturas de até $25 \mathrm{~m}$ e profundidades de $7 \mathrm{~m}$ (COPÉ, 2006; SCHMITZ et al., 2013). 


\section{ARQUEOLOGIA DA PAISAGEM APLICADA AO ESTUDO DE SÍTIOS ARQUEOLÓGICOS JÊ MERIDIONAIS NAS BACIAS HIDROGRÁFICAS DOS RIOS FORQUETA E GUAPORÉ/RIO GRANDE DO SUL}

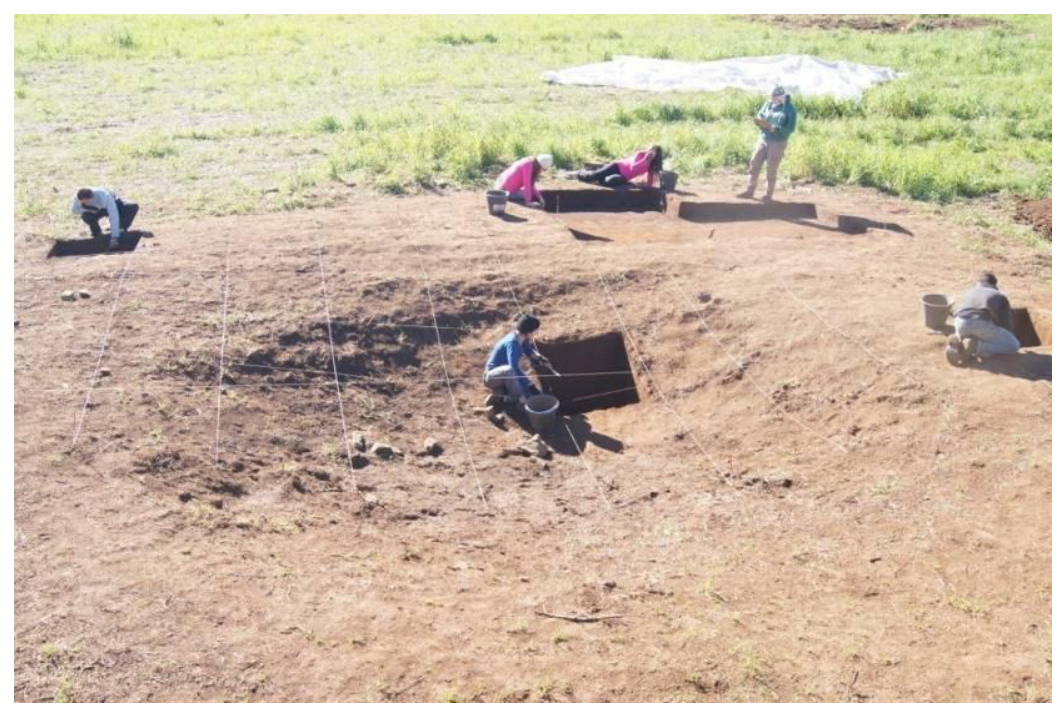

Figura 01 - Escavação de estrutura subterrânea no sítio arqueológico RS-T-126. Fonte: Acervo do Setor de Arqueologia da Univates.

Existe um consenso entre a maioria dos pesquisadores (SCHMITZ et al., 2002; BEBER, 2004; SALDANHA, 2005; COPÉ, 2006; ROGGE e SCHMITZ, 2009; SCHMITZ et. al, 2013) da função habitacional das estruturas subterrâneas. Reis (2007) sugeriu a possibilidade das depressões serem utilizadas para diversos fins, principalmente em virtude de suas dimensões: as menores serviriam como poços de armazenamento; as medianas e grandes como espaços habitacionais, enquanto as extragrandes estariam ligadas a fins cerimoniais.

As cronologias ainda são pouco conhecidas em termos de intensidade $\mathrm{e}$ persistência. Beber (2004) argumenta que o grande número de estruturas em sítios demonstraria uma persistência de ocupação. Segundo o autor, as "casas" não seriam ocupadas todas ao mesmo momento, algumas estariam abandonadas e outras sendo construídas. Em inúmeros sítios se ressalta a ocorrência de eventos de abandono e reocupação após centenas de anos (CORTELETTI, 2008; SALDANHA, 2005), como também de episódios contínuos de ocupação (DE SOUZA et al., 2016) que chegam a 500 anos em uma mesma camada estratigráfica (COPÉ, 2006).
Os sítios superficiais, diferentemente dos sítios de estruturas subterrâneas, são pouco reconhecidos. As áreas com maior densidade de materiais seriam resquícios de unidades domésticas, onde por vezes se encontram fogueiras e marcas de esteio (COPÉ e SALDANHA, 2002; SALDANHA, 2005; COPÉ, 2006). Outros, com a presença de baixas densidades de materiais, com predominância de um conjunto artefatual lítico de grande porte, são interpretados como áreas de atividade específicas e manejo agroflorestal (COPÉ e SALDANHA, 2002; DIAS e HOELTZ, 2010).

As relações diretas entre estas duas categorias de sítios foram pouco exploradas. Saldanha (2005) propôs um modelo de distribuição dos assentamentos em Pinhal da Serra/RS, onde demonstrou uma organização baseada na presença de assentamentos com um número significativo de estruturas subterrâneas, circundados por sítios de estruturas isoladas, sítios superficiais e áreas de sepultamento num raio de $1,8 \mathrm{~km}$, configurando-se como um espaço doméstico de atuação.

Entende-se que uma compreensão da distribuição de ambos as categorias de sítios possibilitam a aproximação de um entendimento 


\section{ARQUEOLOGIA DA PAISAGEM APLICADA AO ESTUDO DE SÍTIOS ARQUEOLÓGICOS JÊ MERIDIONAIS NAS BACIAS HIDROGRÁFICAS DOS RIOS FORQUETA E GUAPORÉ/RIO GRANDE DO SUL}

das dinâmicas sociais presentes nas bacias hidrográficas dos rios Forqueta e Guaporé/RS.

\section{MATERIAIS, MÉTODOS E DESCRIÇÃO DA ÁREA DE ESTUDO}

As bacias hidrográficas dos rios Forqueta e Guaporé se encontram no centro/nordeste do estado do Rio Grande do Sul, pertencendo a Bacia Taquari/Antas, ocupando uma área de aproximadamente $5000 \mathrm{~km}^{2}$ (FIGURA 02).

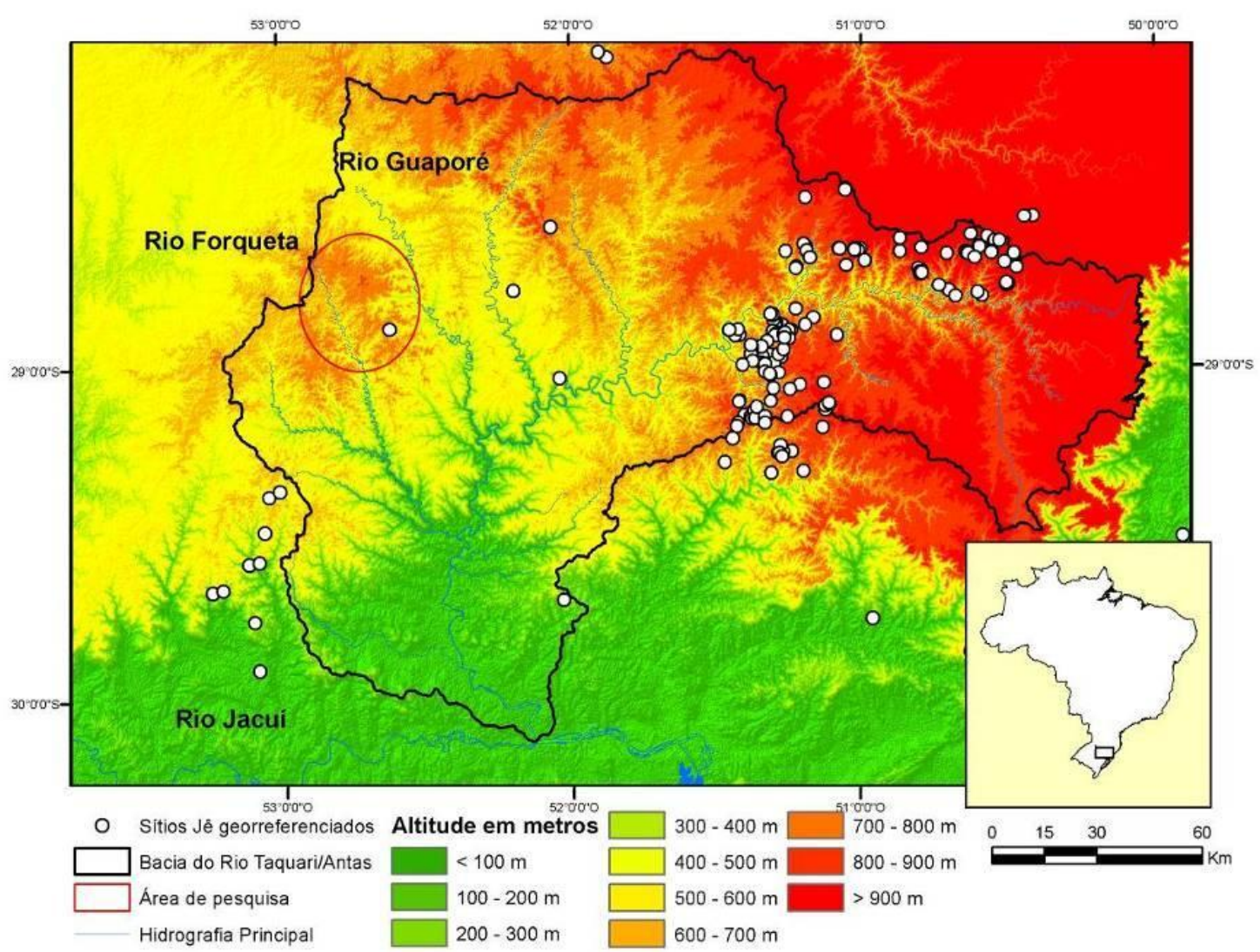

Figura 02 - Identificação da área de estudo no contexto da Bacia do Rio Taquari/Antas e dos sítios arqueológicos Jê Meridionais georreferenciados localizados no Rio Grande do Sul. Fonte: Wolf, Machado e Oliveira, (2016).

Situado geomorfologicamente no Planalto das Araucárias, a região apresenta um ambiente com diferenças significativas no relevo e vegetação, que possibilitam o encontro de espaços distintos em curta distância. Junto às nascentes, apresentam uma formação vegetal caracterizada pela presença do mosaico campo/floresta, com predominância de exemplares da Floresta Ombrófila Mista, relevo plano com pequenas elevações, com altitudes que podem chegar a $900 \mathrm{~m}$. No seu curso intermediário, um vale marcado por um aprofundamento junto a Formação Serra Geral, de rochas basálticas, em forma de $V$, ocasionalmente com formações planas nas proximidades dos recursos hídricos, e altitudes que variam entre 350 e $700 \mathrm{~m}$; cobertas em suas áreas mais baixas pela Floresta Estacional Decidual; enquanto que em altitudes superiores a 400m observa-se um predomínio da Floresta Ombrófila Mista. Próximo à foz no Rio TaquariAntas, o relevo é dominado por planícies de inundação de até $120.000 \mathrm{~m}^{2}$, cobertas pelas águas em períodos de cheia, com predominância da Floresta Estacional Decidual (JUSTUS, MACHADO e FRANCO, 1986; TEIXEIRA e NETO, 1986; VIEIRO e SILVA, 2010). 


\section{ARQUEOLOGIA DA PAISAGEM APLICADA AO ESTUDO DE SÍTIOS ARQUEOLÓGICOS JÊ MERIDIONAIS NAS BACIAS HIDROGRÁFICAS DOS RIOS FORQUETA E GUAPORÉ/RIO GRANDE DO SUL}

A região é alvo de estudos arqueológicos sistemáticos desde o ano 2000, com a inauguração do Setor de Arqueologia da Univates. O primeiro sítio associado às populações Jê Meridionais foi registrado em 2002, composto por 11 estruturas subterrâneas. No mesmo ano se realizou intervenção no sítio, denominado de RS-T-100, não tendo sido identificadas atividades no interior das depressões, interpretando a área entre as estruturas como local de ocorrência das atividades cotidiana do grupo (MACHADO e MILDER, 2005). A partir de 2012 se retomou a pesquisa, com a realização de amplos levantamentos de forma sistemática e intensiva em área piloto de $440 \mathrm{~km}^{2}$.

Esses levantamentos produziram um banco de dados com 68 sítios arqueológicos, sendo 20 representados por estruturas subterrâneas e 48 sítios superficiais. Destes sítios se realizaram novas intervenções em três, sendo dois de estruturas subterrâneas (RS-T-123 e RS-T126) e um sítio superficial (RS-T-130), que possibilitaram a criação de um quadro cronológico composto por 08 datações radiocarbônicas.

Para avaliar o entendimento do espaço criou-se um banco de dados geográficos, com a presença da localização espacial georreferenciada de cada sítio, utilizadas no software ArcGis para confecção de mapas e análises.

\section{RESULTADOS E DISCUSSÕES}

De uma forma geral, os sítios de estruturas subterrâneas se localizam preferencialmente em áreas de divisor de bacia ou na alta encosta, associados à Floresta Ombrófila Mista com transição para áreas de vegetação campestre; em altitudes superiores a $572 \mathrm{~m}$, com média de $711 \mathrm{~m}$. Por sua vez, os sítios superficiais, apesar de encontrados em todos os compartimentos topográficos, existe uma predominância em áreas de fundo de vale, em altitudes a partir de $271 \mathrm{~m}$, associadas a uma zona de transição entre a Floresta Ombrófila Mista e a
Floresta Estacional Decidual (WOLF, MACHADO e OLIVEIRA, 2016).

As intervenções indicam um planejamento prévio do terreno para a construção dos sítios de estruturas subterrâneas, como a presença de um mesmo aterro nivelador (SALDANHA, 2005; IRIARTE et al., 2013). No mesmo sentido, observamos que a maioria das estruturas dos sítios RS-T-123 e RS-T-126 tem uma origem contemporânea, decorrentes de um único ciclo de construção. O sedimento oriundo da escavação era depositado no entorno das estruturas, elevando sua borda; como também utilizado para nivelar o terreno.

As atividades se concentram na parte central das depressões. La Salvia (1987) e Copé (2006; 2015) descrevem a ocorrência de banquetas ou bancadas circundando toda ou parte da circunferência, onde poderiam ser apoiados recipientes cerâmicos e artefatos líticos. Schmitz e Becker (1991) relatam que em casas pouco profundas a parede pode ser em degrau, formando um lanço, após uma banqueta e outro lanço.

Em todas as intervenções realizadas se observou um aprofundamento da porção central onde se concentram as atividades e a cultura material. Em nenhum dos casos se constatou evidências da presença de um esteio central que sustentasse uma possível cobertura (BEBER, 2004). Schmitz et al. (2002) citam a acumulação de materiais na porção central ao longo das ocupações, resultando no entulhamento e nivelamento com as paredes, fator não evidenciado nas estruturas escavadas.

No entorno das estruturas são observadas diferentes áreas de atividades, com a presença de fogueiras e vestígios líticos e cerâmicos. Essas estruturas de fogo apresentam composições e funcionalidades associadas a preparação e consumo de alimentos, como para o aquecimento e luminosidade do assentamento (MACHADO e MILDER, 2005; AZEVEDO, 2014).

O sítio superficial RS-T-130 apresentou uma alta densidade de instrumentos líticos de grande porte evidenciados em superfície próxima a calha do recurso hídrico. Os materiais coletados 


\section{ARQUEOLOGIA DA PAISAGEM APLICADA AO ESTUDO DE SÍTIOS ARQUEOLÓGICOS JÊ MERIDIONAIS NAS BACIAS HIDROGRÁFICAS DOS RIOS FORQUETA E GUAPORÉ/RIO GRANDE DO SUL}

no assentamento, como nos demais sítios superficiais, são compostos por instrumentos lascados bifacial e unifacial, tradicionalmente associadas as atividades de manejo agroflorestal (DIAS, 2003; DIAS e HOELTZ, 2010). A matériaprima utilizada para confecção dos instrumentos encontra origem na calha dos recursos hídricos próximos, e se caracteriza pela baixa redução dos instrumentos, demonstrando pouco investimento. Essa estratégia está relacionada à rápida e esporádica utilização dos sítios, como para a grande oferta de matéria-prima próximas ao uso (ANDREFSKY, 2005; 2008).

Partindo desta relação entre os sítios superficiais e os sítios de estruturas subterrâneas onde ocorrem atividades distintas, interpretamos a ocupação do Alto Forqueta e Guaporé de uma maneira a integrar diferentes perspectivas econômicas do sistema de assentamento Jê Meridional pré-colonial baseada na exploração da parte "alta" e "baixa" do vale.

Parece claro a presença de dois espaços distintos na região: um marcado pela presença de estruturas subterrâneas; e outro marcado pela dominância de sítios superficiais, principalmente líticos. Os primeiros estão relacionados a atividades de maior convívio social, com a ocorrência de alta variabilidade artefatual de instrumentos relacionada a um maior número de atividades (ANDREFSKY, 2005; 2008). Estes sítios apresentam características de áreas domésticas de produção e consumo de alimentos.

Já os sítios superficiais apresentam uma baixa variabilidade artefatual, marcada pela presença de instrumentos de grandes dimensões espalhados por amplas superfícies, ou então concentrados em pequenas áreas. Embora se tenha notado uma relação direta com a proximidade dos recursos hídricos, observa-se que estão a distância de até $100 \mathrm{~m}$ de suas calhas. Relacionadas aos locais de exploração dos grupos, na busca por recursos vegetais, animais e geológicos (DIAS e HOELTZ, 2010). Junto a este manejo e exploração agroflorestal poderiam ser realizadas atividades de caça, coleta e pesca. Mota, Noelli e Silva (1996, p.21) destacam estratégias de pesca através do Pãri, relatadas na etnografia, como identificadas na calha do Rio Ivaí/PR. Seriam armadilhas "constituídas por paredes de pedra feitas para afunilar trechos de rios", conduzindo os peixes a artefatos de madeira ou taquara para aprisionamento.

Os conjuntos densos de estruturas subterrâneas são minoria. Nos sítios onde foi possível obter o número de depressões, constatase um predomínio de sítios com até 3 depressões, com alta incidência de assentamentos com depressões isoladas. Saldanha (2005) observou que os adensamentos de estruturas subterrâneas estão localizados em raios $1,8 \mathrm{~km}$ entre eles, sendo que nesse espaço se localizam outros sítios compostos por estruturas subterrâneas isoladas, sítios superficiais e áreas de sepultamento. Embora não se tenha observado a presença de uma grande concentração de outros assentamentos, percebe-se um padrão semelhante, onde os sítios RS-T-123 (9 estruturas) e RS-T-126 (16 estruturas) estão distantes aproximadamente $4,4 \mathrm{~km}$, num raio de 2,2km. Aplicando-se esse buffer (CHAPMAN, 2009) no entorno dos sítios de densidade $\geq 5$ estruturas, observa-se um padrão de distribuição onde a distância entre os sítios RS-T-100 (11 estruturas) e Jorge Brunetto (5 estruturas) é semelhante a distância entre os sítios RS-T-100 e RS-T-123 (FIGURA 03). 


\section{ARQUEOLOGIA DA PAISAGEM APLICADA AO ESTUDO DE SÍTIOS ARQUEOLÓGICOS JÊ MERIDIONAIS NAS BACIAS HIDROGRÁFICAS DOS RIOS FORQUETA E GUAPORÉ/RIO GRANDE DO SUL}

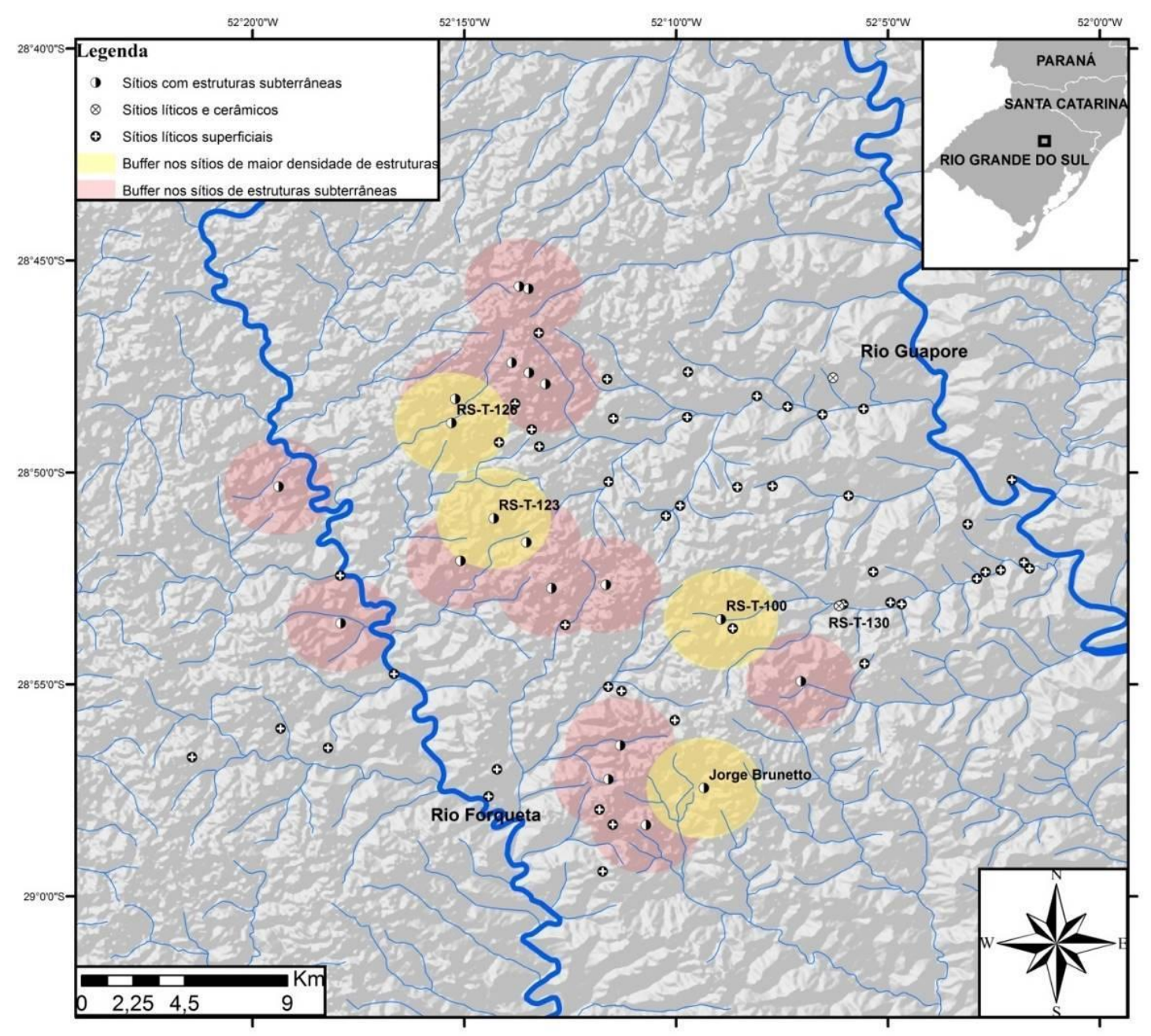

Figura 03 - Aplicação de áreas de influência de 2,2km nos sítios de estruturas subterrâneas. Fonte:

Elaborado pelos autores.

Poucos sítios de estruturas estão presentes no entorno deste buffer, assim como sítios superficiais. Aplicando a mesma técnica a todos os sítios de depressões escavadas, percebe-se um padrão semelhante, com a maioria dos sítios superficiais fora da área abrangida pelo buffer, demonstrando claramente a existência de duas áreas distintas dentro do sistema regional: uma dominada por estruturas subterrâneas e outra por sítios superficiais.

Ao pensarmos em uma territorialidade Jê nas bacias hidrográficas dos rios Forqueta e Guaporé, sugerimos que os assentamentos estão diretamente relacionados à exploração destes dois ecótonos distintos. Embora exista uma semelhança de vegetação e fauna, as pequenas variações existentes poderiam influenciar o deslocamento dos grupos ao acesso de recursos em um curto espaço geográfico.

Tradicionalmente os sítios Jê estão associados às áreas com abundância da Araucaria angustifolia, relacionando a localização à exploração do pinhão, durante período de maturação da semente (SCHMITZ et al., 1988; DIAS, 2003; BEBER, 2004). A intensa utilização das áreas de fundo de vale, como sugerem os dados apresentados, salienta a presença de uma economia mista (IRIARTE e BEHLING, 2007), ligadas a exploração da fauna e flora, como uma possível atividade agrícola, já evidenciada em outras regiões do Sul do Brasil com a ocorrência 


\section{ARQUEOLOGIA DA PAISAGEM APLICADA AO ESTUDO DE SÍTIOS ARQUEOLÓGICOS JÊ MERIDIONAIS NAS BACIAS HIDROGRÁFICAS DOS RIOS FORQUETA E GUAPORÉ/RIO GRANDE DO SUL}

do mesmo fenômeno arqueológico (CORTELETTI et al., 2015).

As 08 datações radiocarbônicas (Tabela 01) realizadas salientam uma ocupação da região por mais de 500 anos, cal. entre 890 e 1415 anos $A D$, sendo evidenciados episódios de reocupação no sítio arqueológico RS-T-126, em ao menos 04 períodos distintos. Outra constatação remete a relação direta entre os sítios superficiais e os assentamentos de estruturas subterrâneas, demonstrando a necessidade de relacionamento destes assentamentos dentro do mesmo sistema. Obviamente as interpretações estão baseadas em poucos sítios, dentro do grande número de áreas evidenciadas, entretanto, possibilitam estas interpretações.

Tabela 1 - Relação das datações radiocarbônicas realizadas em sítios Jê Meridionais nas bacias hidrográficas dos rios Forqueta e Guaporé.

\begin{tabular}{|c|c|c|c|c|c|}
\hline № da Amostra & $\begin{array}{c}\text { Datação não } \\
\text { calibrada } \\
\text { BP }\end{array}$ & $\begin{array}{c}\text { Datação } \\
\text { Calibrada } \\
\text { AD }\end{array}$ & Sítio & Localização & Fonte \\
\hline Beta 385782 & $1140 \pm 30$ & 890 to 1015 AD & $\begin{array}{c}\text { RS-T-126 - } \\
\text { Conjunto } \\
1\end{array}$ & Arvorezinha & $\begin{array}{l}\text { Wolf, Machado } \\
\text { e Oliveira, } 2016\end{array}$ \\
\hline Beta-343953 & $1040 \pm 30$ & 991 to 1148 AD & RS-T-123 & Arvorezinha & $\begin{array}{l}\text { Wolf, Machado } \\
\text { e Oliveira, } 2016\end{array}$ \\
\hline Beta-385781 & $970 \pm 30$ & $\begin{array}{c}1030 \text { to } 1180 \\
\text { AD }\end{array}$ & RS-T-123 & Arvorezinha & $\begin{array}{l}\text { Wolf, Machado } \\
\text { e Oliveira, } 2016\end{array}$ \\
\hline Beta-443959 & $970 \pm 30$ & $\begin{array}{c}1030 \text { to } 1180 \\
\text { AD }\end{array}$ & $\begin{array}{c}\text { RS-T-126 } \\
\text { Conjunto } \\
2\end{array}$ & Arvorezinha & Neste trabalho \\
\hline Beta-343955 & $940 \pm 30$ & $\begin{array}{c}1045 \text { to } 1214 \\
\text { AD }\end{array}$ & RS-T-123 & Arvorezinha & $\begin{array}{l}\text { Wolf, Machado } \\
\text { e Oliveira, } 2016\end{array}$ \\
\hline Beta-423195 & $840 \pm 30$ & $\begin{array}{c}1189 \text { to } 1279 \\
\text { AD }\end{array}$ & RS-T-130 & Arvorezinha & $\begin{array}{l}\text { Wolf, Machado } \\
\text { e Oliveira, } 2016\end{array}$ \\
\hline Beta-443961 & $830 \pm 30$ & $\begin{array}{c}1204 \text { to } 1284 \\
\text { AD }\end{array}$ & $\begin{array}{c}\text { RS-T-126 } \\
\text { Conjunto } \\
1\end{array}$ & Arvorezinha & Neste trabalho \\
\hline Beta-443960 & $630 \pm 30$ & $\begin{array}{c}1304 \text { to } 1415 \\
\text { AD }\end{array}$ & $\begin{array}{c}\text { RS-T-126 } \\
\text { Conjunto } \\
1\end{array}$ & Arvorezinha & Neste trabalho \\
\hline
\end{tabular}

Fonte: elaborada pelos autores

Ao longo deste período o sistema estruturado não apresenta evidências de ruptura, indicando que as estratégias de ocupação e gerenciamento do espaço se mostraram eficientes em virtude da manutenção e exploração do mesmo território ao longo de todo o período de ocupação dos sítios.

\section{CONSIDERAÇÕES FINAIS}

As dinâmicas sociais e culturais das sociedades Jê Meridionais pré-coloniais com o ambiente foram centrais nessa pesquisa. Foi possível evidenciar as influências destas dinâmicas sobre as estratégias de gerenciamento do território abrangido pelas bacias hidrográficas dos rios Forqueta e Guaporé ao longo do tempo, tendo a prática arqueológica cumprida seu papel de trazer a tona essas sociedades. 


\section{ARQUEOLOGIA DA PAISAGEM APLICADA AO ESTUDO DE SÍTIOS ARQUEOLÓGICOS JÊ MERIDIONAIS NAS BACIAS HIDROGRÁFICAS DOS RIOS FORQUETA E GUAPORÉ/RIO GRANDE DO SUL}

A utilização de um conceito amplo de paisagem demonstrou a organização de populações Jê Meridionais na região, baseada na presença de sítios de estruturas subterrâneas e sítios superficiais, a partir da organização em dois espaços distintos. O primeiro relacionado à um maior convívio social, possivelmente relacionadas a unidades habitacionais. Já o segundo indicado pela presença de sítios superficiais de atividades específicas, como o manejo agroflorestal.

Essa diferenciação funcional é observada na distribuição espacial, demarcando áreas específicas dentro do território. Enquanto as unidades residenciais ocupam as porções mais elevadas do terreno; os locais de extração e exploração de recursos concentram-se no fundo dos vales, ligadas a um predomínio de uma vegetação de transição entre a Floresta Ombrófila Mista e a Floresta Estacional Decidual.

\section{REFERÊNCIAS}

ANDREFSKY, W. JR. Lithics: Macroscopic approaches to analysis. Cambridge: Manuals in Archaeology, 2005.

ANDREFSKY, W. JR. Lithic Technology. Cambridge, 2008.

ANSCHUETZ, K. F.; WILSHUSEN, R. H.; SCHEICK, C. L. An Archaeology of Landscapes: Perspectives and Directions. Journal of Archæological Research, vol. 9, no 2, 2001, p. 152-197.

ASHMORE, W.; BLACKMORE, C. Landscape Archaeology. Academic Press: Encyclopedia of Archaeology, 2008, p. 1569-1578.

ASHMORE, W.; WILLEY, G.R. A historical introduction to the study of Lowland Maya settlement patterns. In: ASHMORE, W. Lowland Maya Settlement Patterns, Albuquerque: University of New Mexico Press, 1981, p. 3-18.

AZEVEDO, L. W. Estruturas semi-subterrâneas e galerias: estudo de um caso atípico no Planalto do Rio Grande do Sul. 2010. Monografia (Graduação). Porto Alegre: UFRGS, 2010, 63 fls.
BEBER, M. V. O Sistema de Assentamento das Tradições Taquara-Itararé. 2004. Tese (Doutorado), Programa de Pós-Graduação em História. São Leopoldo: UNISINOS. 2004, 289 fls. BINFORD, L. R. Em busca do passado. Lisboa: Publicações Europa-América, 1983.

CARVALHO JÚNIOR, O. A.; BERBET-BORN, M. L. C.; MARTINS, E. S.; GUIMARÃES, R. F.; GOMES, R. A. T. Ambientes Cársticos. In: FLORENZANO, T. G. Geomorfologia: conceitos e tecnologias atuais. São Paulo (SP): Oficina de Textos, 2008.

CHAPMAN, H. Landscape archaeology and GIS. Stroud: Tempus, 2009.

CLAVAL, P. "A volta do Cultural" na Geografia. Mercator - Revista de Geografia da UFC, ano 01, número 01, 2002.

COPÉ, S.M. Les grands constructeurs precoloniaux du plateau de sud du Bresil: etude de paysages archeologiques a Bom Jesus, Rio Grande do Sul, Bresil. 2006. Tese (Doutorado). Universidade de Paris, 2006, 395 fls.

CORTELETTI, R. Patrimônio Arqueológico de Caxias do Sul. Porto Alegre: Nova Prova, 2008. CORTELETTI, R. Projeto Arqueológico Alto Canoas - PARACA: um estudo da presença Jê no planalto catarinense. 2012. Tese (Doutorado). São Paulo: MAE/USP, 2012, fls, 342.

CORTELETTI, R.; DICKAU, R.; DEBLASIS, P.; IRIARTE, J. Revisiting the economy and mobility of southern proto-Jê (Taquara-Itararé) groups in the southern Brazilian highlands: starch grain and phytoliths analyses from the Bonin site, Urubici, Brazil. Journal of Archaeological Science, 59, p.46-61, 2015.

COSGROVE, D. Social Formation and Symbolic Landscape. New Jersey, Barnes and Noble Books, 1984.

CRIADO BOADO, F. Del terreno al espacio: Planteamentos y perspectivas para la 


\section{ARQUEOLOGIA DA PAISAGEM APLICADA AO ESTUDO DE SÍTIOS ARQUEOLÓGICOS JÊ MERIDIONAIS NAS BACIAS HIDROGRÁFICAS DOS RIOS FORQUETA E GUAPORÉ/RIO GRANDE DO SUL}

Arqueología del Paisaje, CAPA 6, GTArPa, USC. 1999.

DAVIS, B.; THOMAS, J. Landscape Archaeology: Introduction. In: DAVID, B.; THOMAS, J. (Ed.) Handbook of Landscape Archaeology. Left Coast Press, 2010, p. 27-43.

DE SOUZA, J.G; COPÉ, S.M. Novas perspectivas sobre a arquitetura ritual do planalto meridional brasileiro: pesquisas recentes em Pinhal da Serra, RS. Revista da Sociedade de Arqueologia Brasileira, v.23, 2010, p.104-117.

DE SOUZA, J.G. Paisagem ritual no planalto meridional brasileiro: complexos de aterros anelares e montículos funerários Jê do Sul em Pinhal da Serra, RS. Dissertação (Mestrado). São Paulo: MAE/USP, 2012.

DE SOUZA, J.G.; ROBINSON, M.; CORTELETTI, R.; CÁRDENAS, M. L.; WOLF, S.; IRIARTE, J.; MAYLE, F.; DEBLASIS, P. Understanding the chronology and occupation dynamics of oversized pit houses in the southern Brazilian Highlands. Plos One, v.11, 2016b, p. 1 - 24.

DIAS, A. S. Sistemas de assentamento e estilo tecnológico: uma proposta interpretativa para a ocupação pré-colonial do alto vale do rio dos Sinos, Rio Grande do Sul. 2003. Tese (Doutorado). São Paulo: MAE/USP, 2003, $401 \mathrm{fls.}$

DIAS, A. S.; HOELTZ, S. E. Indústrias Líticas em Contexto: O Problema Humaitá na Arqueologia Sul Brasileira. Revista de Arqueologia (Sociedade de Arqueologia Brasileira. Impresso), v. 23, 2010, p. 40-67.

FAGUNDES, M. O conceito de paisagem em arqueologia: os lugares persistentes. HOLOS Environment (Online), v. 09, 2009, p. 135-149.

FEINMAN, G. M. Settlement and Landscape Archaeology. International Encyclopedia of the Social; Behavioral Sciences, 2001, p. 1397 13941.
FISHER, C.T.; THURSON, T.L. Landscape archaeology: towards a definition. Antiquity, 73, 1999, p. 630-631.

FÖRSTER, F.; GROßMANN, R.; HINZ, M.; IWE, K.; KINKEL, H.; ANNEGRET, L.; LUNGERSHAUSEN, U.; MATARESE, C.; MEURER, P.; NELLE, O.; ROBIN, V.; TEICHMANN, M. Towards mutual understanding within interdisciplinary palaeoenvironmental research: An exemplary analysis of the term landscape. Quaternary International, v.312, 2013, p. 4-11.

HEILEN, M.P.; SCHIFFER, M.B.; REID, J.J. Landscape formation processes. In: DAVID, B.; THOMAS, J. (Ed.) Handbook of Landscape Archaeology. Left Coast Press, 2010, p. 601-608. INGOLD, T. The temporality of landscape. World Archaeology, 25 (2), 1993, p. 152-174.

IRIARTE, J.; BEHLING, $H$. The expansion of Araucaria Forest in the southern Brazilian highlands during the last 4000 years and its implications of the Taquara/Itararé Tradition. Enviromental Archaeology, Vol 12, no2, 2007, p. $115-127$

IRIARTE, J.; COPÉ, M.S.; FRADLEY, M.; LOCKHART, J.; GILLAM, C. Sacred landscapes of the southern Brazilian highlands: Understanding southern proto-Jê mound and enclosure complexes. Journal of Antropological Archaeology, 32, 2013, p.74-96.

JUSTUS, J. O.; MACHADO, M. L. A.; FRANCO, M. S. M. Geomorfologia. In: IBGE - Instituto Brasileiro de Geografia e Estatística. Levantamento de Recursos Naturais. Rio de Janeiro: IBGE, v. 33, 1986, p. 313-404.

MACHADO, N. T. G.; MILDER, S. E. S. Prospecções arqueológicas e físico-químicas no sítio RS T 100: estruturas em San Valentin - Ilópolis-RS. In: MILDER, Saul Eduardo Seiguer (Org.) Anais do I Colóquio sobre Sítios Construídos: casas subterrâneas. Santa Maria: Pallotti, 2005. 


\section{ARQUEOLOGIA DA PAISAGEM APLICADA AO ESTUDO DE SÍTIOS ARQUEOLÓGICOS JÊ MERIDIONAIS NAS BACIAS HIDROGRÁFICAS DOS RIOS FORQUETA E GUAPORÉ/RIO GRANDE DO SUL}

METZGER, J.P. O que é ecologia de paisagens? Campinas: Biota Neotropica, v1, n1/2, dez 2001.

OLIVEIRA, M. L. A. A. A vegetação atual do Rio Grande do Sul.In: RIBEIRO, A. M.; BAUERMANN, S. G.; SCHERER, C. S. Monografias da Sociedade Brasileira de Paleontologia, Porto Alegre. p. 6980, 2009.]

REIS, M. J. A problemática arqueológica das estruturas subterrâneas no planalto catarinense. Erechim: Habilis, 2007.

SALDANHA, J. D. M. Paisagem, Lugares e Cultura Material: Uma Arqueologia Espacial das Terras Altas do Sul do Brasil.2005. Dissertação (Mestrado). Programa de Pós-Graduação em História. Porto Alegre: PUCRS, 2005.

SALDANHA, J.D.M. Paisagens e Sepultamentos nas Terras Altas do Sul do Brasil. Revista de Arqueologia, $n^{\circ} 21,2008,85-95$.

SAQUET, M. A. Abordagens e concepções de território. São Paulo: Expressão Popular, 2007.

SCHMITZ, P. I. As Tradições Ceramistas do Planalto Sul-Brasileiro. Arqueologia do Rio Grande do Sul, Brasil, Documento 02. São Leopoldo: IAP, 1988, p. 75-130.

SCHMITZ, P. I.; BECKER, I.I.B.; LA SALVIA, F.; LAZZAROTTO, D.; RIBEIRO, P.A.M. Pesquisas sobre a Tradição Taquara no nordeste do Rio
Grande do Sul. Documentos 02, São Leopoldo: IAP, 1988, p. 5-74.

SCHMITZ, P. I.; ROGGE, J.H. 107 casas subterrâneas no início do povoamento Jê Meridional em Santa Catarina: Rincão dos Albinos. Revista do Museu de Arqueologia e Etnologia, v.21, 2011, p.185-204.

SEGURA, J. S. Redefiniendo el registro material: implicaciones recientes desde la arqueología del paisaje anglosajona. Trabajos de Prehistoria, Vol. 64, no 1, p. 41-64, 2007.

TEIXEIRA, M. B.; NETO, A. B. C. Vegetação. In: IBGE - Instituto Brasileiro de Geografia e Estatística. Levantamento de Recursos Naturais. Rio de Janeiro: V. 33, p. 541-632, 1986.

UNDERHILL, A. P.; FEINMAN, G. M.; NICHOLAS, L. M.; FANG, H.; LUAN, F.; YU, H.; CAI, FENGSHU. Changes in regional settlement patterns and the development of complex societies in southeastern Shandong, China. Journal of Anthropological Archaeology, vol. 27 (1), 2008, p. 1-29

WOLF, S.; MACHADO, N.T.G.; OLIVEIRA, J.L. Arqueologia Regional entre o Forqueta e o Guaporé: o contexto de ocupação Jê Pré-colonial no centro/nordeste do Estado do Rio Grande do Sul. Pelotas: Cadernos do LEPAARQ, vol. XIII, no.26, 2016. 